\title{
UN NUEVO PAÍS. ¿Y AHORA QUÉ? LA INTEGRACIÓN DE LOS INMIGRANTES AFROASIÁTICOS
}

\author{
Lic. D. ${ }^{a} M{ }^{a}$ Ángeles Santiago y Miras \\ Barcelona. España
}

* Desaparecen 32 magrebies al naufragar una patera en Tarifa.

* Un hombre y una mujer embarazada mueren al naufragar una patera en el Estrecho. Un carguero rescató a 19 subsaharianos que aseguran que en la barca habia 28 personas.

* 200 inmigrantes marroquies intentan colarse escondidos en camiones de feria en el puerto de Melilla y amenazaron de muerte a los feriantes, con navajas.

* Estudian traducir el examen de conducir al árabe para magrebies: "(...) El permiso de trabajo no es el ínico "papel" que quieren llevar en la cartera (...)"

El fenómeno de la migración está tomando actualmente un rumbo desenfrenado con los flujos que tienen lugar de Ásia y de África hacia Europa. La puerta más importante para la entrada de las personas provenientes de África, en un mundo nuevo, en un mundo de esperanza, es España, tanto por Canarias como por sus ciudades situadas en el norte del continente africano: Melilla y Ceuta, o Andalucia (Algeciras, Almeria, etc.). De todos es sabido que uno de los lugares elegidos para el paso a lo que estas personas consideran "la tierra de promisión", España, puerta de Europa, es el Estrecho de Gibraltar, el lugar más peligroso debido a las perturbaciones derivadas de ser la confluencia de las corrientes del Océano Atlántico y del Mar Mediterráneo. Todos conocen los riesgos y saben que muchos han perdido la vida, pero no por ello cejan en su afán de empezar una nueva vida, a pesar de las dificultades que ello conlleva. Los que consiguen vencer ese obstáculo natural creen cerrada una etapa vital y que una nueva se alza ante ellos. Pero esa esperanza se torna en decepción, al surgir una serie de problemas que no habían previsto. El primero de ellos es si serán o no aceptados por las autoridades de España. Si no lo consiguen de inmediato, se arriesgan a hacer lo que no pudieron hacer en sus países de origen: manifestaciones, huelgas de hambre... Si alcanzan su sueño se les plantea la cuestión de cómo se podrán integrar en esa nueva cultura. $Y$ ese será otro obstáculo, y uno de los más importantes: ¿Cómo puede una persona que desconoce la lengua de un país integrarse en él y encontrar un puesto de trabajo inmediatamente? Mientras la aprende, ¿cómo subsiste? Puede haber trabajos en donde la necesi- 
dad de comunicación sea mínima. En las tareas del campo, sobre todo en la recolección, unas simples indicaciones con un alto componente de comunicación no verbal pueden ser suficientes. Pero, ¿esa es la expectativa de vida que se habían planteado cuando decidieron abandonar su pais hacia la tierra de promisión? ¿Han expuesto su vida para recolectar campos, cuidar de los animales o limpiar coches?

Para integrarse totalmente en la nueva sociedad necesitan la herramienta esencial: el conocimiento de la lengua, el instrumento que les ayude a comunicarse, a tramitar los permisos de residencia y de trabajo, en una palabra, el elemento esencial para poder sobrevivir y poder llegar a ser esos seres humanos que han soñado, unos seres con unas expectativas de futuro para ellos y para sus hijos, totalmente alejadas de las que se les presentaban en sus paises, en donde la pobreza y el hambre les acosaban constantemente.

Es necesario que los gobiernos entiendan -en este caso, el español, que es el que más sufre esta problemática- la importancia de crear centros educativos en los puntos en donde la inmigración es más abundante. En ellos se enseñaría a estas personas nuestro idioma y les sería mucho más sencillo moverse por el resto de España.

Se debería concienciar igualmente a la sociedad europea de que las personas que abandonan su país generalmente no lo hacen por gusto, sino que se ven obligados a emigrar debido a diferentes problemas, ya sean de trabajo, políticos o a guerras. Deberiamos preguntarnos qué sucedería si la situación se diera a la inversa, es decir, si fuéramos los europeos los que por las mismas razones tuviéramos que abandonar nuestra patria e ir a un pais del que desconocemos su lengua y su cultura, como durante los años 40,50 y 60 pasó con muchos españoles que tuvieron que emigrar a Francia, Alemania, Gran Bretaña, Suiza e Italia, pero aquí se plantea una cuestión que no siempre se daba entre los emigrantes españoles, el problema de la reagrupación familiar. Primero llega a nuestro país el padre, en gran número de ocasiones acompañados del mayor de sus hijos. Cuando tienen trabajo y un techo donde cobijarse, traen a sus esposas y al resto de sus hijos, y así, familias enteras se trasladan a otro lugar lejano del propio de origen. Ese es el caso de dos alumnos de 11 años que asisten a la escuela en donde imparto clases, aunque en el mismo colegio se encuentran muchos niños más.

Un problema añadido son los menores indocumentados. Muchos de ellos no tienen referentes familiares en sus países ( $y$ en esta caso me refiero a lo más cercano, a Marruecos) porque muchos de ellos huyeron de sus casas o fueron abandonados y, por lo tanto, antes de venir a España ya vivían en la calle. Un número considerable de ellos prefiere seguir malviviendo y vagabundeando antes de acceder a ser acogidos en albergues, porque creen que si aceptan la oferta de las autoridades estarán subyugados y deberán cumplir unas normas. $Y$ esa situación hace tiempo que se vive, por ejemplo, aqui en Melilla.

En ocasiones es muy difícil saber cuántos menores existen en esa situación, para que puedan ser tutelados por el Estado, porque al haber entrado de manera ilegal no están censados o no ha dado tiempo a localizarlos. No debemos olvidar que el Estado, bajo los auspicios de la Administración, está obligado, por leyes y convenios internacionales, a hacerse cargo de cualquier menor desamparado.

En el caso de Cataluña, la región de España en que resido, el Departamento de Justicia de Gobierno Autónomo presentó en septiembre unos datos en donde constaba que había 
unos 290 menores magrebies desamparados, en su mayoria acogidos en centros gubernamentales o en familias y que una parte de este colectivo (entre 50 y 70 adolescentes) se mostraba reticente a integrarse en centros de acogida y prefería vivir en la calle. A estos jóvenes son a los que se les atribuye actos delictivos, porque de alguna manera tienen que subsistir.

Otro problema con el que se encuentran, aunque muchas personas del país de acogida no lo quieran reconocer, es el racismo, algo innato en el ser humano, quien tiende en principio a rechazar, en una primera impresión, todo aquello que le parece diferente o lo que no entiende. Esta es la principal causa de que a veces estas gentes se encuentren con un ambiente hostil que no comprenden y del que no saben cómo salir.

Los gobiernos que se encuentran con este problema deberian intentar buscar soluciones para que todos convivamos en armonia, tanto los nativos del país como los que llegan a él, y uno de ellos sería, como ya he ido repitiendo, enseñarles nuestra lengua y nuestra cultura antes de que se distribuyan por el territorio español.

Una cuestión a tener en cuenta, por la importancia que representa, es que muchos de estos tienen unos oficios o unos estudios de grado medio y superior, titulaciones que les permitiría acceder al puesto de trabajo para el que dichos estudios les capacitan, pero se encuentra con que en un gran número de ocasiones éstas no son suficientes para poder ejercer sus respectivas profesiones en España o en cualquier pais de Europa, con lo que deben acudir a las escuelas de Formación Profesional, o en algunos casos a las Universidades, para realizar aquellas asignaturas que les faltan para obtener la nivelación de su título, cuando no deben volver a realizar los correspondientes estudios para poder ejercer su profesión en nuestro pais, pues sus títulos no son homologables, al provenir de sistemas educativos diferentes al nuestro.

Pero como considero que uno de los elementos esenciales, quizás el más importante, es el conocimiento del código comunicativo, lo ideal para la integración de estas personas sería que alguien que conociese su lengua les orientase para que pudieran realizar sin dificultad tareas que nosotros realizamos habitualmente: ir a comprar, saber orientarse en un transporte público, enseñarles los lugares en los que pueden atenderles si se ponen enfermos o si necesitan asesoramiento jurídico para tramitar los permisos de residencia y de trabajo, entenderse en la escuela con los profesores de sus hijos, etc.

Algunos inmigrantes adultos saben algo de español, pero no lo suficiente como para integrarse en la sociedad, aunque sí para comunicarse mínimamente. Algunas mujeres musulmanas, por ejemplo, al llevar a sus hijos a la escuela se sienten tan cohibidas que optan por no dirigirse al profesorado. Cuando no tienen más remedio que comunicarse con el profesor algunas de ellas prefieren tomar a sus hijos como intérpretes, quienes intentan, con lo poco que hayan podido aprender, hacer de nexo entre sus madres y sus profesores.

En otras ocasiones, estos padres optan por ir a la escuela con un intérprete, una persona de su raza que lleva en el país mucho más años que ellos y que, por lo tanto, domina algo la lengua. Quienes no tienen quienes les acompañen intentan hacerse entender, pero los maestros vemos su angustia y su impotencia ante la situación, tanto cuando preguntan sobre sus hijos como cuando vienen a informarse sobre el contenido de los comunicados que periódicamente se les envia, angustia que, por otro lado, se nos transmite al profesorado, al vernos en la misma situación de impotencia comunicativa. 
Si dificil es para los adultos esta adaptación, mucho más lo es para sus hijos, abocados a ser inmersos en un sistema de enseñanza totalmente diferente al de su pais, con una lengua totalmente desconocida para ellos y sabiendo que unos conocimientos básicos no los van a poder adquirir, porque les falta la herramienta que les permitirá comprender lo que el profesor les plantea: el conocimiento del código comunicativo del país de destino, en este caso, el español.

El problema se agrava si se asientan en una región en la que conviven dos lenguas, puesto que los niños son escolarizados, no en la lengua del país, sino en la lengua de la comunidad autónoma en que residen, como es el caso de Cataluña, Galicia o País Vasco, zonas en donde los niños son escolarizados en catalán, gallego o vascuence, respectivamente, sin posibilidad de recibir clases en español, que es la lengua que les servirá para poder desplazarse por la geografia nacional, con lo que la movilidad del futuro se les restringe.

Los niños musulmanes que tienen adquirida la lectoescritura se enfrentan al problema de aprender un nuevo código escrito: un alfabeto, unas sílabas, una sintaxis y una morfología totalmente diferente a la suya, el alifato.

Las trabas y los problemas continúan en todas las asignaturas.

En una actividad de lengua, cuando sus compañeros lean en voz alta un texto y lo comenten, estarán marginados, porque no podrán realizar esta actividad; como mucho, se limitarán a copiar el texto, un texto del que desconocerán su contenido y que se limitarán a transcribir. En las clases de ciencias sociales y de ciencias naturales las únicas actividades que podrán efectuar serán copiar unos textos sin sentido para ellos y dibujar y pintar las diferentes láminas del libro de texto o que el profesor le proporcione especialmente para que al menos, de manera visual, entiendan parte de lo que se está haciendo en la clase.

Asignaturas como matemáticas les serán incomprensibles. Si conocen el mecanismo de las operaciones básicas, el profesor está limitado a planteárselas para que las practiquen, al ser dichos mecanismo comunes a todos los idiomas, pero no podrá esperar que desarrollen el mismo problema que le plantea al resto de la clase, porque les falta la herramienta esencial: el conocimiento de la lengua -tanto a nivel oral como escrito- en que se expresan las personas con las que convive.

Las actividades que estos niños pueden llevar a cabo en el aula son muy restringidas: Si se realiza un mural para exponer en un pasillo, lo único que se puede esperar de ellos es que pinten un dibujo o que ayuden a llevarlo de un sitio a otro. No podrán participar en él exponiendo su criterio tanto en el contenido como en el formato del mismo, por lo tanto, estarán discriminados.

Los profesores nos encontramos, pues, con unos chiquillos de los que desconocemos su cultura, sus costumbres, los porqués de algunos de sus comportamientos, que a veces provienen de elementos culturales propios; con unos padres con los que nos es imposible comunicarnos y saber mediante ellos cómo son sus hijos y qué estrategias siguen para poder encauzarlos. Tampoco podemos explicarles qué hemos visto en ellos de bueno y de malo, para poder ponernos de acuerdo en cómo llegar a un objetivo final: formarles como seres humanos, con unos principios, a los que intentamos darles unas bases que les sirvan para desarrollar su mente y que sean capaces de pensar por sí mismos, para que así crezcan en libertad, porque nos falta el elemento de enlace esencial para comunicarnos con ellos: la lengua. 
En gran número de ocasiones, esta situación de incomprensión de las tares que se desarrollan en el aula lleva al niño a realizar unas funciones típicas de su condición infantil: distraer y molestar a los demás, con la consiguiente distorsión de la marcha de la clase.

Un choque importante lo encontramos cuando las niñas musulmanas reciben las clases de Educación Física. Para muchas de ellas, según la zona de la que provengan, supone un cambio radical de sus estructuras mentales, porque hacer gimnasia implica expresare con su cuerpo, dar rienda suelta al movimiento y, por lo tanto, realizar actividades que en su país les están vetadas.

Actuaciones en la escuela para poder atender a estos menores inmigrantes con situación familiar estable debería ser labor de las correspondientes Consejerías de Educación de los gobiernos de las Comunidades Autónomas, que para ello tienen traspasadas todas las competencias. Y esa ayuda por parte de la Administración deberia hacerse dándole al profesorado la orientación de cómo deben proceder con estos alumnos, mediante reuniones mensuales con personas que sepan cómo funcionan los sistemas educativos de origen de estos niños, qué materias se imparten en sus escuelas y a qué niveles según la edad. Ellos podrían ayudar al profesorado a evaluar a estos alumnos para que realmente se pudiera llevar a cabo el proceso que derivaria en la tan traída y llevada "igualdad de oportunidades". Esta sería la verdadera "atención a la diversidad", y no la fiesta anual bajo este epígrafe que se celebra en algunas comunidades autónomas, con la que los gobernantes creen haber zanjado el problema y limpiado sus conciencias; fiesta a la que, después de todo, quienes menos asisten son los inmigrantes; fiesta que hace creer que el problema queda zanjado, con lo que se olvida de él hasta el año siguiente, cuando toque celebrar la nueva "Fiesta de la atención a la diversidad". Y ese dinero, que debería haberse invertido en Servicios Sociales para ayudar realmente a cubrir las necesidades básica de estas personas, se despilfarra en fiestas y fiestones que sólo sirven para cubrir el expediente sobre el tratamiento del tema en la correspondiente comunidad autónoma.

Por otra parte, los maestros nos encontramos en las escuelas con niños (procedentes mayoritariamente del continente africano) que desconocen totalmente nuestra lengua y nuestras costumbres. Se les coloca de manera artificial en los cursos en los que, por su edad, deberían estar en nuestro país, y las dificultades crecen, porque no se les puede realizar una prueba de nivel para ver en qué curso pueden ser colocados, al no existir profesorado cualificado para ello. Desconocemos los sistemas educativos de sus países de origen y, por lo tanto, es posible que tengamos a niños en cuarto curso con un nivel de conocimientos básicos de primero o posiblemente de sexto, pero nos será muy dificil averiguarlo porque tenemos la barrera de la comunicación.

A algunas escuelas se envían profesores de apoyo. En la escuela en la que imparto clase, en concreto, el profesor de apoyo destinado por la Administración para efectuar el seguimiento de los niños de incorporación tardía acude al centro tres veces por semana, en dos sesiones de tres cuartos de hora cada uno de esos días, en total, seis sesiones: 4 horas y media semanales, para impartir lengua oral.

Estos profesores de apoyo, aun teniéndolos en grupos reducidos, no pueden evaluar la actitud de estos alumnos en el interior del aula normal, ni la evolución que llevan a cabo, porque en algunas escuelas, como la que yo imparto clases, en un municipio de la provincia de Barcelona, San Andrés de la Barca, ya son 41 los chicos magrebíes y, en segundo, por- 
que con el corto espacio de tiempo que estos profesionales de la enseñanza emplean para observarlos, les es prácticamente imposible ver la evolución y el aprovechamiento de las clases. Su única misión queda restringida a enseñarles la lengua vehicular en la que recibirán sus clases, en este caso, el catalán.

Muchos niños magrebíes se incorporan a la escuela una vez que el curso ha comenzado. Conforme van llegando se les acoge siguiendo unos Planes de incorporación tardía que se han visto obligados a replanificar, ante la nueva e inesperada situación que se ha presentado: la llegada masiva de personas de otra cultura y de otra lengua.

En paralelo, los maestros de la escuela imparten clases de lengua y también de matemáticas, en dos sesiones de 45 minutos semanales: una para lengua y otra para matemáticas.

A principios del curso 99-00 asistían al aula de incorporación tardía los seis niños magrebies matriculados. Durante la primera quincena de enero se matricularon cinco más, a fines de enero, cuatro y a primeros de mayo, dos, con lo que ya eran 17.

En este curso, el 00-01, ya hay 41 alumnos de estas características y es previsible que a partir de enero se incorporen más, puesto que muchos alumnos son hijos de guardias civiles residentes en el cuartel de esta población, y éstos han sido destinados a otros lugares de España, con lo que es previsible que estas vacantes las sean cubiertas por los niños magrebíes que vayan llegando a la localidad, data la ley que ha aprobado el gobierno autónomo de Cataluña en donde queda reflejado que el $20 \%$ de las plazas vacantes de las escuelas de esta región se reservarán a inmigrantes.

Esta cantidad incontrolada, por imprevisible, de niños magrebíes a lo largo del pasado curso y lo que llevamos de este ha obligado al centro a efectuar una reestructuración de los horarios del profesor de apoyo, pues hubo de formarse un segundo grupo y dividir el tiempo destinado a cada grupo, quedando restringido el refuerzo a tres sesiones semanales de 45 minutos cada una, para lengua oral.

Sería aconsejable también que maestros de sus países de origen que se hayan asentado aquí asesoraran a los maestros de las escuelas en las que asisten alumnos de estos países para que, mientras aprenden la lengua y las costumbres, no vayan perdidos y al menos tengan una mínima conciencia de cómo deben actuar y si es correcta la metodología que están utilizando para hacerse entender y para comprender a los alumnos.

El Sistema Educativo español, a pesar de sus carencias, cada vez mayores, sobre todo en el campo de las Humanidades, según se desprende de los últimos estudios, es mucho más completo que el que siguen estos alumnos. Los niños que provienen de la zona del magreb, por ejemplo, se encuentran que en su nueva escuela deben aprender unas asignaturas que en sus países de origen no se imparten, tales como la geografia, la historia o las ciencias naturales. Unos alumnos musulmanes de 11 años me cuentan que en su ciudad de origen únicamente estudiaban tamazigth, árabe, francés, matemáticas y El Corán.

El MEC debería enviar a todas las escuelas de España un informe detallado de los sistemas educativos vigentes en los paises de origen de los emigrados, para que asi el profesorado español pueda tener un punto de referencia de los conocimientos mínimos que poseen estos niños.

Mientras esta solución llega, deberemos convivir lo mejor posible, e intentar que los que llegan a nuestro país se encuentren como en el suyo propio. 